\title{
Coupled numerical simulations of mitigation measures for local heat island effect in an urban neighborhood
}

\author{
Aytaç Kubilay $^{1}$, Dominique Derome ${ }^{1}$, Jan Carmeliet ${ }^{2}$ \\ ${ }^{1}$ Laboratory for Multiscale Studies in Building Physics, Empa Swiss Federal Laboratories for \\ Materials Science and Technology, Dübendorf, Switzerland \\ ${ }^{2}$ Chair of Building Physics, Swiss Federal Institute of Technology ETH, Zurich, Switzerland
}

\begin{abstract}
The extent and duration of evaporative cooling, as a countermeasure to urban heat island effect, depend on factors such as moisture availability and material liquid capacity and permeability. The present study investigates the evaporative-cooling potential of conventional urban materials and green surfaces on a historical public square in the city of Zurich with a particular focus on the pedestrian thermal comfort during a heat wave. The numerical model couples computational fluid dynamics (CFD) simulations of wind flow with the heat and moisture transport (HAM) in urban materials in order to document the behavior of urban materials in terms of moisture storage and transport in urban settings. By resolving the physical processes at urban local scale, we aim to provide a framework for the development of sustainable and resilient solutions for local heat islands.
\end{abstract}

\section{Introduction}

The built environment directly influences the urban climate based on its characteristics regarding building configuration and choice of urban materials. Urban areas are generally accompanied with an increase in sensible heat storage and in radiation entrapment and a decrease in evapotranspiration, factors that all together lead to the urban heat island (UHI) effect. Mitigation measures for the UHI, such as the use of high albedo materials, evaporative cooling, vegetation and shading devices, can improve outdoor thermal comfort, building energy use and public health.

There is a considerable amount of research on the impact of each of the aforementioned mitigation measures (Toparlar et al., 2017). However, in the majority of studies, moisture transport is simplified by applying a uniform latent heat flux or, in some cases, neglected altogether. Furthermore, some studies consider uniform values of surface temperature at large parts of the domain. While it can be argued that these simplifications are valid at larger scales, e.g. regional or city scale, urban climate at local scale $(<100 \mathrm{~m})$ require a more detailed consideration of the coupling between different physical processes.

From the aspect of pedestrian-level outdoor thermal comfort, accurate estimation of local surface temperatures and local wind-flow field is necessary, especially when comparing different UHI mitigation measures. At local scale, air transport is significantly influenced by air-surface temperature differences as buoyancy can alter the flow regime (Allegrini et al., 2013). Research on evaporative cooling at porous urban materials in an isolated street canyon shows that the rate of evaporation from porous surfaces and, as a result, reduction in surface temperature depend on, among other variables, wind speed (Saneinejad et al., 2014), liquid permeability of material as well as moisture distribution and availability (Kubilay et al., 2018b; 2019). Similarly, transpiration from vegetation depends on the water availability in the soil (Manickathan et al., 2018), which is a key aspect for evapotranspiration to function as a mitigation measure. Such study requires that coupled heat and moisture transport in porous media is taken into account in addition to the air domain. Therefore, resolving moisture storage and transport in urban materials at local level is necessary for accurate estimation of evaporative cooling. In addition, the impact of evaporative cooling on thermal comfort depends on the building configuration and, therefore, would be different in an urban neighborhood compared with a simpler arrangement of buildings, e.g. a street canyon.

The present study investigates the evaporative-cooling potential of conventional porous urban materials and green surfaces by coupling computational fluid dynamics (CFD) simulations of wind flow with heat and moisture transport (HAM) in urban porous materials. The model is applied on an urban neighborhood in the city of Zurich with a particular focus on the thermal comfort within a public square. The cooling mechanisms at varying conditions and the resulting local thermal comfort are analyzed in detail. Thermal comfort is modeled based on the Universal Thermal Comfort Index (UTCI), which provides locally the perceived temperature based on the mean radiant temperature, air temperature, relative humidity and wind speed (Fiala et al., 2012; Bröde et al., 2012). The results allow for the investigation of how particular mitigation measures for UHI effect, or combinations of them, perform under varying atmospherical conditions.

\section{Methodology}

The coupled model consists of separate submodels to solve for the transport in the air subdomain, for the longwave (thermal) and short-wave (solar) radiation, for the absorption, transport and storage of heat and moisture in the subdomains representing porous urban materials and for vegetation. The model is implemented into 
OpenFOAM v6 (2018). The general framework and the detailed methodology of the model are given in Kubilay et al. (2018a).

\section{Numerical modeling of transport in the air}

The wind flow is solved using Reynolds-averaged Navier-Stokes (RANS) with the realizable $k-\varepsilon$ model. Additionally, transport equations for the turbulent and convective transport of heat and moisture are solved. Heat is considered as an active scalar, where buoyancy is modeled by using a compressible formulation of the Navier-Stokes equations and calculating air density based on the ideal gas law. Moisture is modeled as a passive scalar, where the transported quantity is the humidity ratio, i.e. the ratio of the mass of water vapor to the mass of dry air.

\section{Numerical modeling of radiation}

Short-wave (solar) and long-wave (thermal) radiative fluxes between the domain surfaces and with the sky are calculated with separate systems of linear equations based on a radiosity approach. The incoming solar radiation is composed of direct and diffuse components. The direct component of incoming solar radiation is calculated with ray tracing in order to take into account the occurrence of shading over the day. Multiple reflections of both solar and thermal radiation are calculated using view factors, which are calculated based on algebraic relations between surfaces.

Air is considered as a non-participating medium, i.e. absorption, scattering and emission of radiation by air are neglected. All building surfaces are assumed opaque to both longwave and shortwave radiation. The model further assumes that surfaces are grey and reflections are diffuse, i.e. properties are independent of wavelength and direction.

\section{Numerical modeling of porous urban materials}

In the solid subdomains, which model porous urban materials, the transport of heat and moisture (HAM) is solved. The present study uses the continuum modeling approach, where the different phases are not distinguished separately at a certain point in the material but, instead, the macroscopic behavior of the porous material is modeled. The coupled heat and moisture transport equations are given in equations (1) and (2), respectively (Janssen et al., 2007):

$$
\begin{gathered}
\left(c_{0} \rho_{0}+c_{l} w\right) \frac{\partial T}{\partial t}=-\nabla\left(q_{c}+q_{a}\right) \\
\frac{\partial w}{\partial p_{c}} \frac{\partial p_{c}}{\partial t}=-\nabla\left(g_{l}+g_{v}\right)
\end{gathered}
$$

where $c_{0}$ denotes the specific heat of dry material, $\rho_{0}$ the density of dry material, $c_{l}$ the specific heat of liquid water, $w$ the moisture content, $T$ absolute temperature and $p_{c}$ capillary pressure. The derivative $\partial w / \partial p_{\mathrm{c}}$ represents the moisture capacity of the porous material. On the right hand side, $q_{c}$ and $q_{a}$ denote the conductive and advective heat fluxes, whereas $g_{l}$ and $g_{v}$ denote liquid and vapor moisture fluxes. The advective heat transfer represents the heat flow due to vapor and liquid flow including latent heat transport. Vapor flux includes transport due to capillary pressure gradient and due to temperature gradient.

The implemented HAM model is verified by comparing with HAMSTAD (Heat Air and Moisture STAndards Development) benchmark study (Hagentoft et al., 2004) which is specifically developed for moisture transport in building materials. Benchmark case 4 models onedimensional transport within a building facade composed of brick as load-bearing material and a hygroscopic interior finishing. The facade is exposed to subsequent heat and moisture loads at the inner and outer surfaces for a duration of 120 hours. Figure 1 compares the variation of exterior surface temperature and moisture content over time. Black lines denote the range of results in the benchmark provided by numerical models from six different research institutions. The initial rise in moisture content is due to condensation, while the subsequent wetting and drying cycles are due to rain load and solar radiation. From the results, it is concluded that the present model successfully captures the strongly coupled physical process.

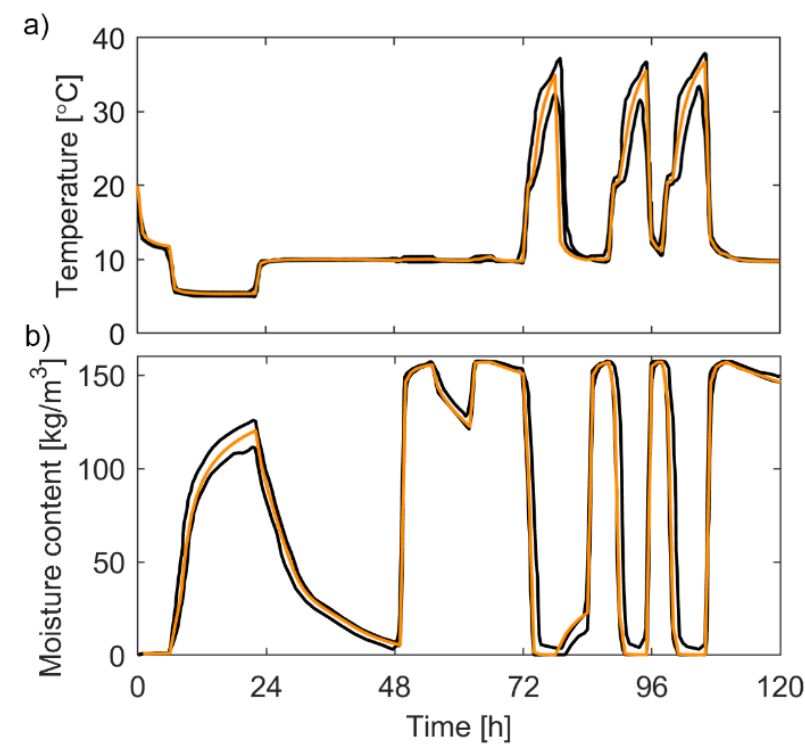

Figure 1: Comparison of a) temperature and b) moisture content at the exterior surface. Black: range of data from Hagentoft et al. (2004), orange: present model.

\section{Numerical modeling of grass-covered surfaces}

Grass is modeled using a leaf energy model, assuming a stationary leaf energy balance and neglecting the dynamic thermal storage of heat in leaves. The stationary energy balance at the leaf is given as:

$$
q_{\text {rad }, l}-q_{\text {sen }, l}-q_{\text {lat }, l}=0
$$

where $q_{\mathrm{rad}, \mathrm{l}}$ is the net (positive for absorbed) radiative flux (solar and thermal) at the leaf surface, $q_{\text {sen,l }}$ the sensible heat flux and $q_{\text {lat, }}$ the latent heat flux.

The absorbed solar radiation at the leaf can be defined as follows:

$$
q_{\text {rad,l }}^{s}=\left(1-\tau_{l}-\rho_{l}\right) q_{\text {rad,inc }}^{s}
$$

where $\tau_{1}$ denotes the transmissivity and $\rho_{1}$ the reflectivity of leaf for solar radiation and $q_{\text {rad,inc }}^{\mathrm{s}}$ is the incoming 
solar radiation. Transmissivity is modeled based on the Beer-Lambert law:

$$
\tau_{l}=e^{-\beta L A I}
$$

where $\beta$ denotes the extinction coefficient for solar radiation and LAI the leaf area intensity. The transmitted solar radiation is absorbed by the soil underneath.

The sensible heat flux due to convective heat transfer from leaf surface to the air is given as:

$$
q_{s e n, l}=h_{c, h}\left(T_{l}-T\right)
$$

where $h_{\mathrm{c}, \mathrm{h}}$ denotes the convective heat transfer coefficient at the leaf surface, $T_{1}$ the leaf temperature and $T$ the air temperature.

The latent heat flux at the leaf surface is defined as:

$$
q_{l a t, l}=h_{c, m}\left(p_{v, l}-p_{v}\right)
$$

where $h_{c, \mathrm{~m}}$ denotes the convective mass transfer coefficient at the leaf surface, $p_{\mathrm{v}, 1}$ the vapor pressure at the leaf stomata and $p_{\mathrm{v}}$ the vapor pressure of the air above leaf surface. $p_{\mathrm{v}, \mathrm{l}}$ is close to the saturation vapor pressure at leaf temperature. The convective mass transfer coefficient at the leaf surface is a function of stomatal resistance, which is a function of solar radiative flux and vapor pressure deficit in the air (Manickathan et al., 2018). Grass leaf temperature is calculated with an iterative energy balance calculation based on Eqs. (3)(7). Once the calculation for the grass layer is performed, source/sink terms for heat, mass and momentum fluxes are imposed in the air.

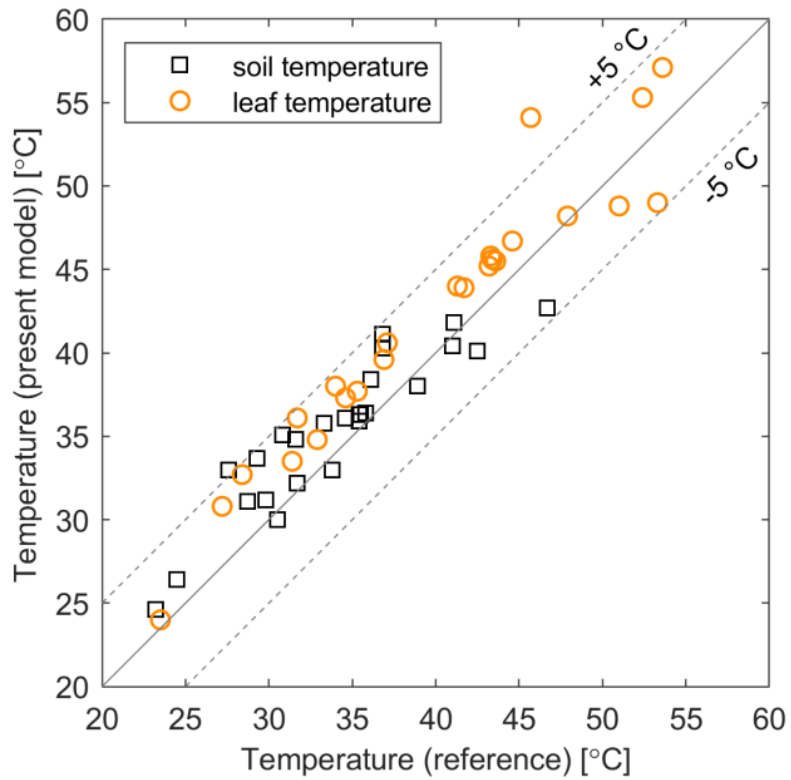

Figure 2: Comparison of soil surface and leaf temperatures between the reference study (Tabares-

Valesco and Srebric, 2012) and present model.

The implemented grass model is verified by comparing the grass leaf temperature and the soil surface temperature underneath with a numerical study performed by Tabares-Valesco and Srebric (2012), which provides a detailed parametric study on green roofs, validated with laboratory experiments within an environmental chamber. In this case, the present grass model is coupled with the air flow calculation and the transport within the soil. The comparison covers a range of wind speed, air temperature, solar radiation, relative humidity, stomatal resistance and LAI. Each point in Figure 2 denotes the steady state value of leaf and soil temperatures for a separate configuration. Values are mostly in quite good agreement and within a difference of $5^{\circ} \mathrm{C}$. The largest discrepancies are observed when the wind speed is at the lowest, i.e. buoyancy forces dominate within the environmental chamber, and at very high or very low LAI.

\section{Coupling algorithm and convergence criteria}

The coupling between the air and porous solid subdomains is performed by sequentially solving the steady RANS equations in the air and the unsteady heat and moisture transfer in porous building materials. This approach is valid due to the fact that the time scale of transport in building materials is larger than the time scale of transport in air.

Transient heat and mass transport in porous domains are simulated using adaptive time steps (Janssen et al., 2007), during which the solution of the air domain remains constant. At each time step, internal iterations between heat and moisture equations are performed until temperature and moisture content values converge, while the thermal radiative heat fluxes are updated accordingly. Finally, the new values for temperature and moisture are used to solve the steady air flow for the next exchange time step. This information exchange between domains is repeated at each exchange time step (Saneinejad et al., 2014). In this study, an exchange time step of $10 \mathrm{~min}$ is chosen.

At the coupled boundaries of the air subdomain, Dirichlet boundary conditions are used, where the values for temperature and humidity ratio calculated for the urban materials are defined. Neumann boundary conditions are used at the coupled exterior surfaces of urban materials, where the moisture flux comprises the convective vapor exchange and the heat flux comprises the convective heat transfer, the radiative heat transfer and the latent and sensible heat transfer due to vapor exchange.

\section{Simulation settings}

\section{Computational domain and grid}

The computational domain representing part of the Zurich city center and its dimensions are given in Figure 3a. The height of the buildings in the computational domain varies between 20 and $79 \mathrm{~m}$. The minimum distance between the buildings and the lateral boundaries of the domain are $420 \mathrm{~m}$. The largest blockage ratio for any wind direction is $3.4 \%$, which satisfies the best practice guidelines stated in Franke et al. (2011). Part of Lake Zurich is also visible in Figure 3a to the south of the buildings. From the lake, the Limmat river, flows towards North. A close-up view of the public square "Münsterhof" is shown in Figure 3b together with the computational grid on the surfaces.

The computational grid has been generated with snappyHexMesh utility, which comes with OpenFOAM 
and requires the surface geometry of the buildings as input, e.g. in .stl format. The resolution in terms of the geometric details of buildings and the computational cells around Münsterhof is defined separately for each layer of buildings that are indicated with different colors in Figure 3a. The shapes of the buildings in the immediate surroundings of Münsterhof are captured more accurately, while the buildings in the outermost layer are modeled simpler. Buildings further away are not modeled explicitly, but only through a surface roughness on the ground. The computational cells are refined towards the Münsterhof. The resulting computational grid is composed of about 4.1 million cells, which are mainly of hexahedral shape. The smallest cell height is about $0.3 \mathrm{~m}$ on the building surfaces in order to capture the surface shape well.

a)
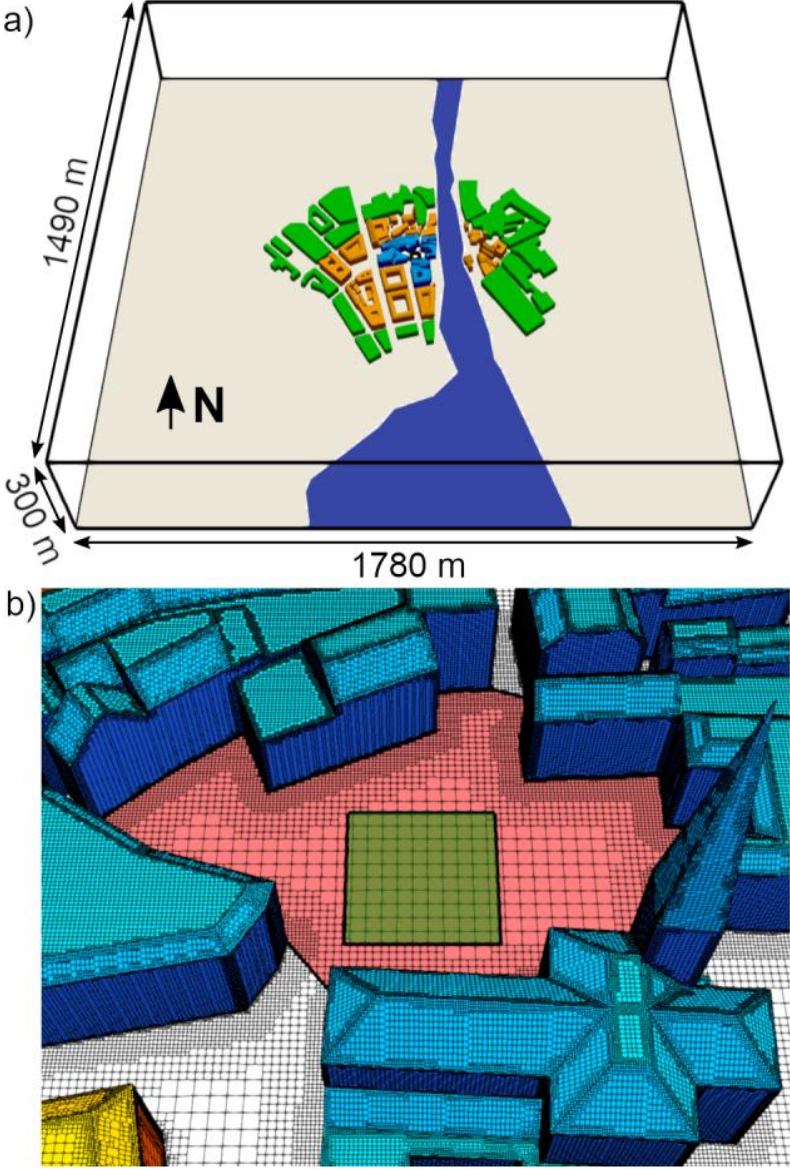

Figure 3: a) Computational domain. b) Computational grid on the surfaces of the Münsterhof, the area in green measures $25 \times 25 \mathrm{~m}^{2}$.

\section{Meteorological conditions}

The variations of ambient temperature and total solar radiation intensity are based on June $29^{\text {th }} 2015$, during a heat wave in Zurich, Switzerland. Wind speed at $10 \mathrm{~m}$ height, wind direction and air temperature given in Figure 4 are obtained in 1-hour intervals based on earlier COSMO simulations coupled with Double Canyon Effect Parameterization (DCEP) urban canopy model (Schubert et al., 2012; Mussetti et al., 2018) and represent the meteorological conditions in the vicinity of Münsterhof. The ambient temperature, here defined as the temperature above the canopy, varies between $17.6^{\circ} \mathrm{C}$ and $27.1^{\circ} \mathrm{C}$. The ambient relative humidity is taken as varying between $40 \%-70 \%$, the lowest value being in the afternoon. Wind direction is from south for most of the day, except for a few hours in the afternoon. Clear sky conditions are considered throughout the day.

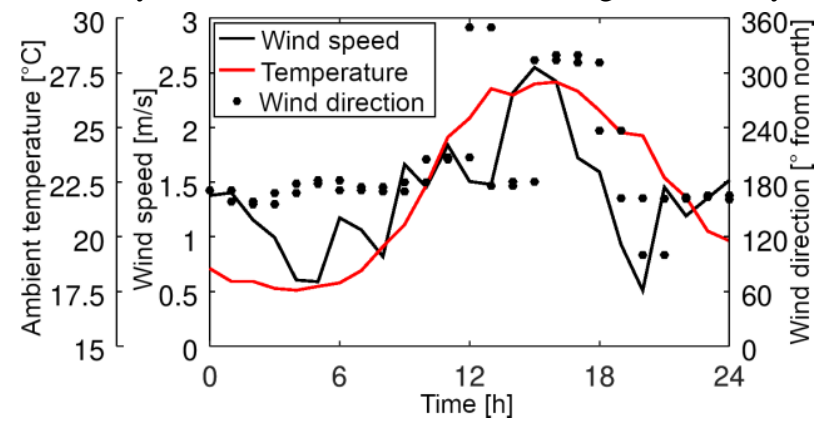

Figure 4: Meteorological conditions obtained from COSMO simulations (Mussetti et al., 2018) at the location of Münsterhof on June $29^{\text {th }} 2015$ in Zurich.

\section{Description of the case study}

The ground surface of the Münsterhof, indicated with red and green in Figure $3 b$, is modeled as a coupled boundary, where heat and moisture exchange occurring between the air and the urban porous materials is explicitly solved using Eqs. (1) and (2). For this, a threedimensional subdomain is generated by extruding the ground surface downwards.

Three different configurations are considered for the Münsterhof ground as shown in Figure 5. Case 1 is composed of a top layer of concrete with $30-\mathrm{cm}$ thickness. Beneath this layer, a soil layer with a depth of $1.70 \mathrm{~m}$ is present. The concrete layer within the rectangular zone of $25 \times 25 \mathrm{~m}^{2}$, indicated with green in Figure $3 b$, is replaced with brick in case 2 and with grass-covered soil in case 3 . The remaining parts of the ground outside the green rectangular zone are identical to case 1 .

Moisture properties, namely the wetting moisture retention and liquid permeability, of the materials considered are given in Figure 6. Concrete has a very limited moisture absorption and reaches capillary moisture content already at very large capillary pressure (Hagentoft et al., 2004), while soil (Schaap et al., 1998; Janssen et al., 2002) and brick (Hagentoft et al., 2004) have relatively higher liquid permeability. Soil holds the highest amount of water among all three when saturated. Due to the much lower liquid permeability of concrete, case 1 is considered as a reference case with negligible moisture transfer at the surface.

The rate of evaporation from porous urban surfaces is high as long as there is liquid water present at the top pores and material surface is at almost $100 \% \mathrm{RH}$. At these conditions, i.e. first drying phase, the drying rate depends mainly on external conditions. The high rate of evaporation can be sustained as long as capillary transport within the material can replace the water loss at the top surface. At similar level of partial wetting conditions, brick shows relatively longer first drying 
phase than soil based on the moisture properties given in Figure 3 (Kubilay et al., 2018b; 2019).

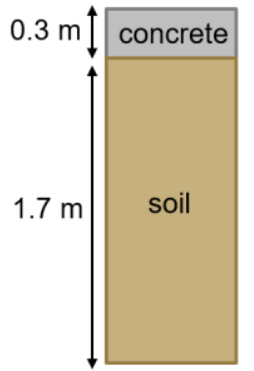

Case 1

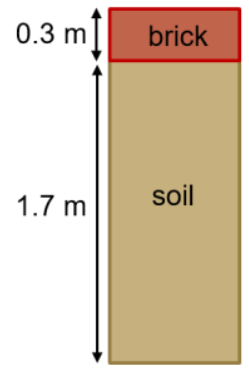

Case 2



Case 3

Figure 5: Cross sections of the Münsterhof ground within the green zone (Not drawn to scale).

a)

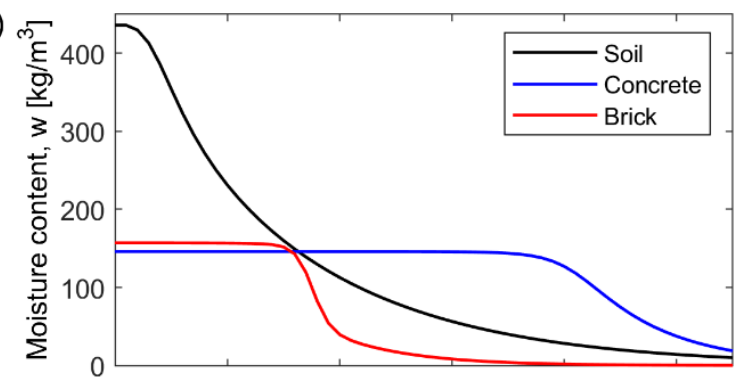

b)

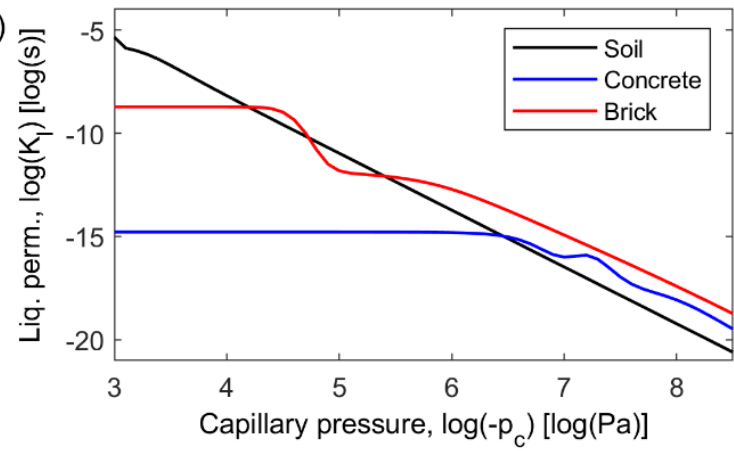

Figure 6: a) Wetting moisture retention and b) liquid permeability for soil, concrete and brick.

For each case, the ground materials have been initialized with a uniform temperature of $21^{\circ} \mathrm{C}$. For concrete and brick a relative humidity of $60 \%$ is set, while the soil saturation is set to $20 \%$. Then, the simulations are run for several days using the ambient boundary conditions in Figure 4 until an equilibrium daily thermal cycle is obtained. Therefore, the results represent thermal conditions following a build-up over a period of heat wave and are independent from the initial values. It is assumed that enough moisture is available in the soil to sustain a low stomatal resistance and, hence, a relatively high transpiration rate for grass. Note also that, except for evapotranspiration of grass, latent heat flux is negligible at the surface due to relatively low moisture content at the top pores of concrete, brick and soil as a result of heat wave. Therefore, as an additional measure to enhance evaporative cooling, brick in case 2 and the upper $0.3 \mathrm{~m}$ of the soil in case 3 are wetted at capillary moisture content. Wetting can be performed by using stored rain water or similar other means. Note that the practical implementation of wetting mechanism is outside the scope of the present study.

At the bottom of the soil layer, a constant temperature of $10^{\circ} \mathrm{C}$ and a constant moisture saturation of $20 \%$ are set. Note that the daily fluctuation of external loads do not reach the total depth of $2 \mathrm{~m}$. The lateral boundaries of the porous material layers are assumed adiabatic and impermeable. The thermal properties for the materials are given in Table 1. The remaining surfaces, such as ground, building facades and roofs, are assumed impermeable and their surface temperatures are obtained from the earlier COSMO simulations (Mussetti et al., 2018). A constant water surface temperature of $20.9^{\circ} \mathrm{C}$ is taken for the lake and the river. The wall surfaces within the computational domain, i.e. roof, wall, ground, have a uniform emissivity of 0.9 and albedo of 0.2 . Grass blades of $10 \mathrm{~cm}$ height are considered in case 3 with a leaf area intensity of 2.0.

Table 1: Thermal properties of the materials used in porous media, where $w$ denotes moisture content.

\begin{tabular}{|c|c|c|c|}
\hline Material & $\begin{array}{c}\text { Density } \\
{[\mathbf{k g} / \mathbf{m} 3]}\end{array}$ & $\begin{array}{c}\text { Specific heat } \\
{[\mathbf{J} / \mathbf{k g K}]}\end{array}$ & $\begin{array}{c}\text { Thermal } \\
\text { conductivity } \\
{[\mathbf{W} / \mathbf{m K}]}\end{array}$ \\
\hline Soil & 1150 & 650 & 1.5 \\
\hline Concrete & 2280 & 800 & $1.5+1.58 \mathrm{E}-2 \times \mathrm{W}$ \\
\hline Brick & 2005 & 840 & $0.5+4.5 \mathrm{E}-3 \times \mathrm{W}$ \\
\hline
\end{tabular}

\section{Results}

Contours of the magnitude of wind velocity and the difference of air temperature from the ambient air above the canopy are given in Figures 7 and 8, respectively, at a height of $2 \mathrm{~m}$ at different times of the day. The arrows indicate the predominant wind direction. The wind-flow fields indicate that the river acts as a ventilation lane with minimum sheltering from the buildings. Furthermore, for wind from south, air enters inside the Münsterhof from the riverside, which can be seen at time instants 06:00, 18:00 and 00:00. This brings in the relatively cooler air inside the Münsterhof, which is not the case at 12:00.

By using case 1 with concrete cover as reference, Figures $9 \mathrm{a}$ and $9 \mathrm{~b}$ compare the variation of average surface temperature for wet brick (case 2) and for grasscovered soil (case 3, soil both dry and wet), respectively. For case 3, temperature of the grass blades and the soil underneath are given separately. The highest temperature is observed at the concrete surface which heats up until about $57^{\circ} \mathrm{C}$. For case 2 (wet brick), a significantly lower surface temperature is observed compared to the case with concrete. The temperature difference is also maintained at the times where the rate of evaporation is dominated by solar radiation, which indicates that there is still liquid water present within the brick layer and that the brick is able to replenish the lost amount of water at its surface. 


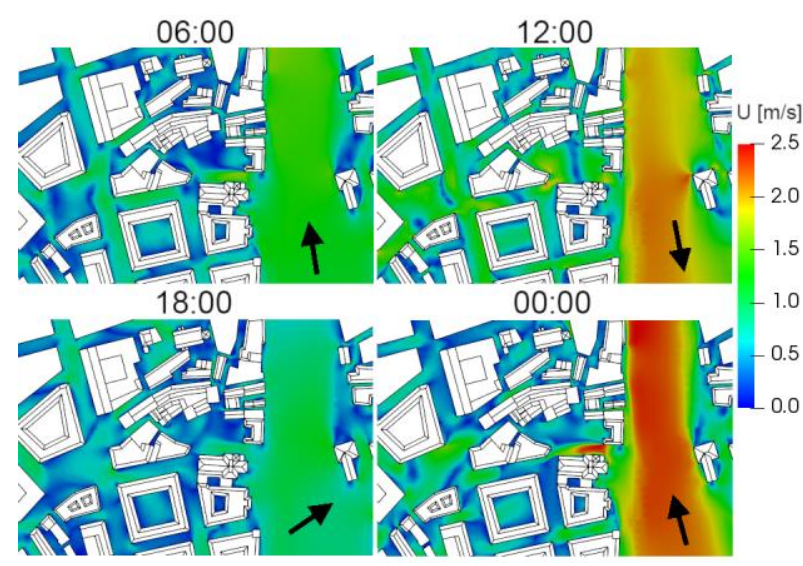

Figure 7: Magnitude of wind velocity at different times of the day at $2 \mathrm{~m}$ height for case 1. Arrows indicate the predominant wind direction.

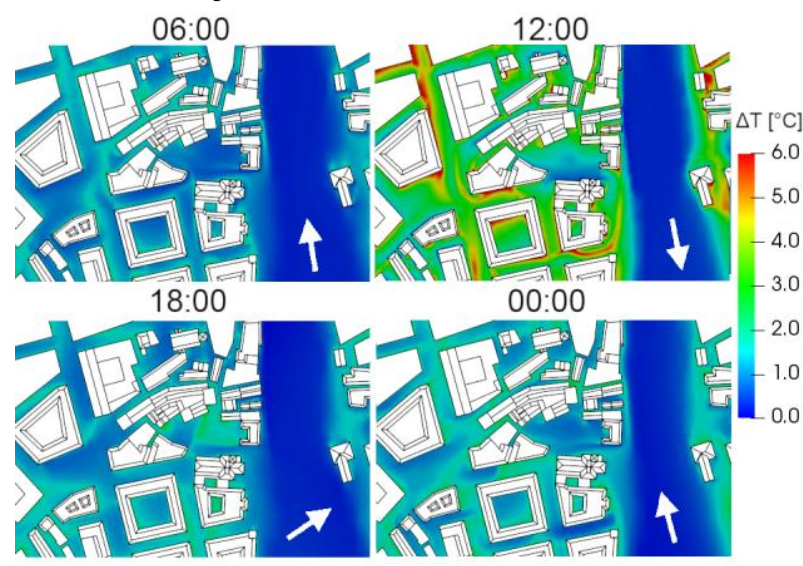

Figure 8: Local air temperature difference with respect to the temperature above the canopy at different times of the day at $2 \mathrm{~m}$ height for case 1 .

In comparison, the latent heat flux from the non-wetted soil surface in case 3 is much lower. This is mainly due to the fact that the liquid permeability of soil at $20 \%$ saturation is several order of magnitudes lower than the one of brick at saturation. As a result, the maximum surface temperature for dry soil in Figure $9 \mathrm{~b}$ reaches a relatively high value of $53^{\circ} \mathrm{C}$. Note that soil has a larger thermal diffusivity than concrete, but also a lower volumetric heat capacity. Assuming that the latent heat flux for non-wetted soil is low, the main difference in surface heat fluxes between case 1 is the radiative fluxes. The soil surface is partially shaded by grass. The shading by grass coverage pushes the surface temperature lower during the day, but also larger at night due to limited thermal radiative losses to the sky. At the same time, the temperature of the grass blades is significantly lower as a result of evapotranspiration. The other factors playing a role in the temperature difference between the nonwetted soil surface and grass are the neglected heat capacity of grass blades and the more efficient convective heat removal due to the larger surface area of grass blades than the soil surface.

In the case where the upper part of soil is also wetted, a significantly lower soil surface temperature is obtained due to additional evaporation. Note that the obtained temperature is also lower than case 2 with wet brick due to the fact that solar radiation reaching soil is lower than the one reaching brick. This decrease in soil temperature also lowers the grass temperature slightly due to the radiative exchange between soil and due to slightly lower air temperature.
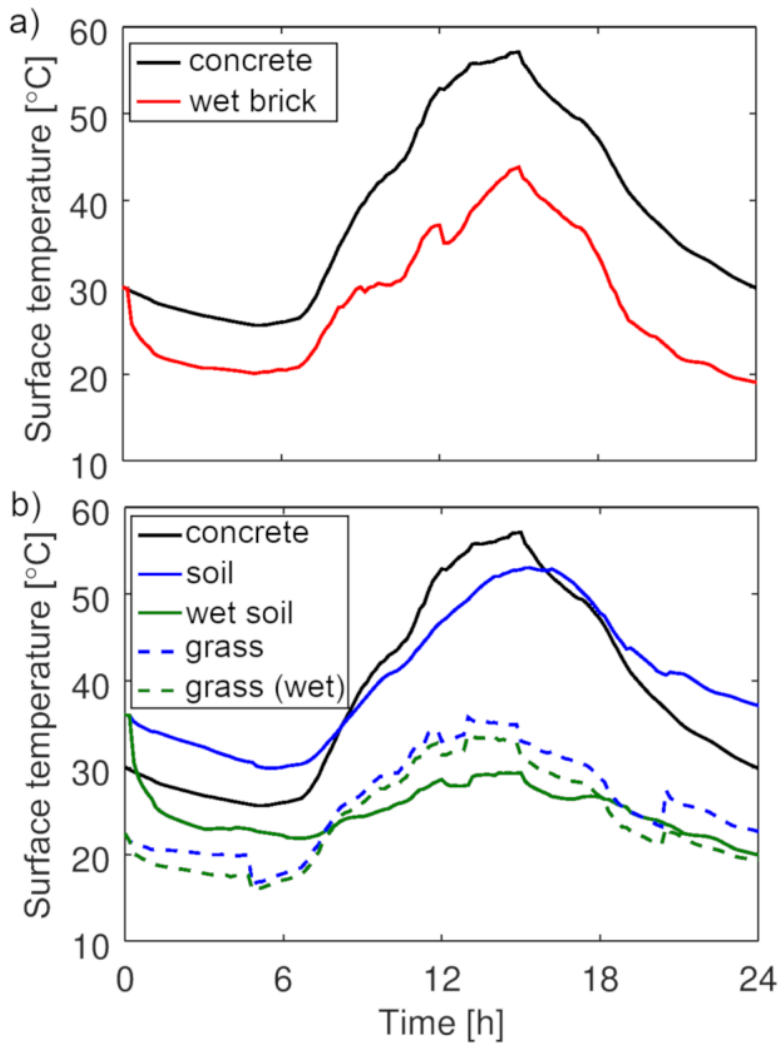

Figure 9: Variations of average surface temperature of a) case 2 (wet brick) and case 3 (grass with non-wetted and wet soil) at the rectangular zone in comparison to case 1 (concrete).



Figure 10: Variations of thermal comfort index at the rectangular zone for cases 1 (concrete), 2 (brick) and 3 (grass with non-wetted and wet soil).

The UTCI values obtained with different surfaces are given in Figure 10 for a person standing at the center of the rectangular zone. For the grass-covered surface, the mean radiant temperature is calculated using the grass temperature, assuming that the surface is fully covered with grass. The highest UTCI values indicate a strong thermal heat stress according to the classification in 
Bröde et al. (2012). In general, a similar range of values are observed for the cases with brick and grass, where the resulting UTCI values are up to about $3^{\circ} \mathrm{C}$ lower for the grass-covered than the ones for the concrete surface.

\section{Discussion and conclusion}

The influence of urban surface covers in a public square in Zurich is investigated. In particular, the impact of evaporative cooling on the thermal comfort within the square is analyzed. The applied numerical model couples computational fluid dynamics (CFD) simulations of wind flow with the heat and moisture transport (HAM) in urban materials. This way, the coupled heat and moisture transport in urban materials is resolved at local scale.

The cooling potential obtained with the grass-covered and brick surfaces depend on various parameters including, but not limited to, liquid transport properties, initial conditions of surface layer and soil moisture availability. The present study provides an initial analysis in a real environment with an aim to obtain and compare the range of improvement in external thermal comfort by use of separate approaches focusing on evaporative cooling. Note that there are several other parameters that were not considered in the present study, such as the leaf area intensity of grass cover and thickness of the top layer material. Therefore, more extensive parametric study and sensitivity analysis are necessary in order to provide general conclusions. Nevertheless, the results can provide insight on the comparison and optimization of different strategies that aim to improve urban microclimate. As the model resolves the three dimensional moisture transport within the urban materials, solutions such as "smart wetting" of materials, e.g. varying the wetting period and wetting amount and the use of permeable materials, e.g. varying the porosity and pore size distribution, towards optimizing the cooling and providing thermal comfort can be investigated in detail. Such solutions can provide additional ways to improve thermal comfort during a heat wave, e.g. as a mitigation measure. Furthermore, the coupled model can help estimate the impact of extreme weather conditions such as drought, during which vegetation would be unable to provide cooling through transpiration.

\section{Acknowledgement}

This research project is supported by the Swiss Competence Center for Energy Research SCCER FEEB\&D of the Swiss Innovation Agency lnnosuisse and the Swiss National Science Foundation (SNF) Project no. 169323.

\section{References}

Allegrini, J., Dorer, V. and J. Carmeliet (2013). Wind tunnel measurements of buoyant flows in street canyons. Building and Environment 59, 315-326.

Bröde, P., Fiala, D., Blazejczyk, K., Holmér, I., Jendritzky, G., Kampmann, B., Tinz, B. and G. Havenith (2012). Deriving the operational procedure for the Universal Thermal Climate Index (UTCI). International Journal of Biometeorology 56, 481494.

Fiala, D., Havenith, G., Bröde, P., Kampmann, B. and G. Jendritzky (2012). UTCI-Fiala multi-node model of human heat transfer and temperature regulation. International Journal of Biometeorology 56, 429441.

Franke, J., Hellsten, A., Schlunzen, K.H. and B. Carissimo (2011). The COST 732 Best Practice Guideline for CFD simulation of flows in the urban environment: a summary. International Journal of Environment and Pollution 44, 419-427.

Hagentoft, C.-E., Kalagasidis, A.S., Adl-Zarrabi, B., Roels, S., Carmeliet, J., Hens, H., Grunewald, J., Funk, M., Becker, R., Shamir, D., Adan, O., Brocken, H., Kumaran, K. and R. Djebbar (2004). Assessment Method of Numerical Prediction Models for Combined Heat, Air and Moisture Transfer in Building Components: Benchmarks for Onedimensional Cases. Journal of Thermal Envelope and Building Science 27, 327-352.

Janssen, H., Carmeliet, J. and H. Hens (2002). The influence of soil moisture in the unsaturated zone on the heat loss from buildings via the ground. Journal of Building Physics 25, 275-298.

Janssen, H., Blocken, B. and J. Carmeliet (2007). Conservative modelling of the moisture and heat transfer in building components under atmospheric excitation. International Journal of Heat and Mass Transfer 50, 1128-1140.

Kubilay, A., Derome, D. and J. Carmeliet (2018a). Coupling of physical phenomena in urban microclimate: A model integrating air flow, winddriven rain, radiation and transport in building materials. Urban Climate 24, 398-418.

Kubilay, A., Carmeliet, J. and D. Derome (2018b). Using rain and vegetation to improve thermal comfort in a hot street canyon with fully-integrated urban climate modeling. Proceedings from the $7^{\text {th }}$ International Building Physics Conference. Syracuse, NY (USA), 23-26 September.

Kubilay, A., Derome, D. and J. Carmeliet (2019). Impact of evaporative cooling due to wetting of urban materials on local thermal comfort in a street canyon. Sustainable Cities and Society 49, 101574.

Manickathan, L., Defraeye, T., Allegrini, J., Derome, D. and J. Carmeliet (2018). Parametric study of the influence of environmental factors and tree properties on the transpirative cooling effect of trees. Agricultural and Forest Meteorology 248, 259-274.

Mussetti, G., Brunner, D., Allegrini, J., Wicki, A., Schubert, S. and J. Carmeliet (2018). On the importance of simulating urban climate at subkilometre scale for a realistic representation of the 
intra-urban variability. International Journal of Climatology 40, 458-476.

OpenFOAM (2018). OpenFOAM v6.0 User Guide. The OpenFOAM Foundation. http://www.openfoam.org

Saneinejad, S., Moonen, P. and J. Carmeliet (2014). Coupled CFD, radiation and porous media model for evaluating the micro-climate in an urban environment. Journal of Wind Engineering and Industrial Aerodynamics 128, 1-11.

Schaap, M.G., Leij, F.J. and M.T. Van Genuchten (1998). Neural network analysis for hierarchical prediction of soil hydraulic properties. Soil Science Society of America Journal 62, 847-855.
Schubert, S., Grossman-Clarke, S. and A. Martilli (2012). A Double-Canyon Radiation Scheme for Multi-Layer Urban Canopy Models. Boundary-Layer Meteorology 145, 439-468.

Tabares-Valesco, P.C. and J. Srebric (2012). A heat transfer model for assessment of plant based roofing systems in summer conditions. Building and Environment 49, 310-323.

Toparlar, Y., Blocken, B., Maiheu, B. and G.J.F. van Heijst (2017). A review on the CFD analysis of urban microclimate. Renewable and Sustainable Energy Reviews 80, 1613-1640. 